\title{
Characterization of Annur and Bedakam Ecotypes of Coconut from Kerala State, India, Using Microsatellite Markers
}

\author{
M. K. Rajesh, ${ }^{1}$ K. Samsudeen, ${ }^{1}$ P. Rejusha, ${ }^{1}$ C. Manjula, ${ }^{1,2}$ \\ Shafeeq Rahman, ${ }^{1}$ and Anitha Karun ${ }^{1}$ \\ ${ }^{1}$ Division of Crop Improvement, Central Plantation Crops Research Institute, Kasaragod Kerala, 671124, India \\ ${ }^{2}$ Nehru Arts and Science College, Kanhangad Kerala, 671314, India \\ Correspondence should be addressed to M. K. Rajesh; mkraju.cpcri@gmail.com
}

Received 30 September 2013; Revised 20 December 2013; Accepted 26 December 2013; Published 23 February 2014

Academic Editor: Arianna Azzellino

Copyright (C) 2014 M. K. Rajesh et al. This is an open access article distributed under the Creative Commons Attribution License, which permits unrestricted use, distribution, and reproduction in any medium, provided the original work is properly cited.

\begin{abstract}
The coconut palm is versatile in its adaptability to a wide range of soil and climatic conditions. A long history of its cultivation has resulted in development of many ecotypes, which are adapted to various agro-eco factors prevalent in a particular region. These ecotypes usually are known by the location where they are grown. It is important to explore such adaptation in the coconut population for better utilization of these ecotypes in coconut breeding programs. The aim of the present study was to identify the genetic diversity of the Bedakam and Annur ecotypes of coconut and compare these ecotypes with predominant West Coast Tall (WCT) populations, from which they are presumed to have been derived, using microsatellite markers. All the 17 microsatellite markers used in the study revealed $100 \%$ polymorphism. The clustering analysis showed that Annur and Bedakam ecotypes were two separate and distinct populations compared to WCT. It was also evident from the clustering that Annur ecotype was closer to WCT than Bedakam ecotype.
\end{abstract}

\section{Introduction}

Coconut (Cocos nucifera L.), a monotypic species, is one of the major perennial oil crops of the tropics. The palm forms the basis in many developing countries for food products as well as serving industrial purposes [1]. It is often referred to as "Kalpavriksa," the tree which provides all the necessities of life. The coconut palm is versatile in its adaptability to a wide range of soil and climatic conditions. In India, it grows well in coastal alluvium of both the West and East coasts, river alluvium of the deltaic regions, and the literate and red loam soil of the inland areas. It is estimated that about $70 \%$ of the cropped area is under sandy loam soil. Sandy loam soil with good cation-exchange capacity and soil water level at about $4 \mathrm{~m}$ depth is considered as the best soil type for coconut [2]. Coconut cultivars are generally classified into tall and dwarf types. The tall types are primarily outcrossing, while the dwarf types are predominantly self-pollinated [3]. In a cultivar, certain members have been reported to differ from one another in a single or a constellation of characters [4].
Coconut is a perennial crop with indeterminate flowering and the productive features of the palm are considerably influenced by environmental variables; weather factors like sunshine hours, light intensity, ambient temperature, humidity, and rainfall have been reported to play a significant role in fluctuations of coconut yield $[5,6]$. The influence of seasonal variations on gas exchange characteristics and biochemical constituents of coconut palms in a particular area have also been reported in earlier studies [7-10]. Weather factors are known to influence crop production especially under rainfall condition and of all the climatic factors, rainfall has maximum influence on the seasonal variation in yield [11]. Variations in environmental factors usually cause genotypes to respond differently from one environment to another resulting in genotype environmental interactions.

The understanding of the distribution of a particular species is also dependent on knowledge of the interrelationship of particular species to their environment. There are wide variations in the crop and cultivation method in different regions. 
Ecotypes are cultivars which are grown for a long period to be superior to other local cultivars by the farmers. Wide morphological variability has been observed in these native populations of coconut in various coconut growing countries of the world. Studies have indicated high genetic variability and diversity for whole nut weight, husked nuts weight, kernel weight, copra weight, copra and oil yield of the palms [12]. In India, coconut is generally considered to be a crop of coastal region, even though it is found to be grown well in inlands like Assam State of India [13].

Genetic diversity is thought of as the amount of genetic variability among individuals of a variety, or population of a species [14]. Assessment of genetic diversity of a population provides valuable information that can decide its proper utilization, sustainable management, and design of conservation strategies. There are different techniques available to assess genetic diversity. Among these, molecular markers have the potential to significantly increase the efficiency of coconut genetic improvement, specifically in the areas of germplasm management, genotype identification, and marker-assisted selection of economically important traits [15]. Microsatellites or simple sequence repeats (SSRs) are tandemly repeated motifs of 1-6 bases found in all prokaryotic and eukaryotic genomes analyzed to date. They are present in both coding and noncoding regions and are usually characterized by a high degree of length polymorphism. The origin of such polymorphism is still under debate though it appears most likely to be due to slippage events during DNA replication [16]. The increased number of SSR markers has greatly improved the knowledge about the genetic diversity/relationships between coconut varieties/populations [17-20].

One of the major coconut growing states in India is Kerala, where the most popular variety grown by the farmers is the West Coast Tall (WCT), which occupies over 95 percent of the area under coconut. The WCT palm grows well in all types of soil and is relatively tolerant to moisture stress. It is recommended for large scale cultivation in the coastal regions of Kerala and Karnataka states of India [21]. WCT cultivar has spread inwards from the coastal regions and is now found cultivated even in high ranges. In the process, the cultivar diverged into different ecotypes known by the location where they are cultivated, some of them being Annur, Bedakam, Kuttiyadi, Attingal, and Kanjirappally. These diverse coconut ecotypes have been reported to exhibit morphological or physiological phenotypic differences. The objective of this study was to decipher the genetic diversity among Annur (ANR) and Bedakam (BDK) ecotypes of coconut from Kerala State, India, and compare them with WCT populations, from which they are presumed to have been derived, using molecular markers, which might throw light on the crop's evolutionary diversification.

\section{Materials and Methods}

2.1. Plant Materials and DNA Extraction. The plant material for this study consisted of 50 leaf samples collected from the two different ecotypes, namely, ANR (17 palms) from Kannur district and BDK (16 palms) from Kasaragod district, both in Kerala State of India, and WCT cultivar (17 palms) from CPCRI, Kasaragod, Kerala State. Genomic DNA was extracted from spindle leaves of palms following the standardized protocol [22]. The DNA was quantified spectrophotometrically and the bands were checked on $0.8 \%$ agarose gel electrophoresis.

2.2. Molecular Analysis. A total of 17 SSR primer pairs specific to coconut were used in the present study to assess the genetic diversity of the respective coconut collections (Table 1). The PCR reactions were carried out in $20 \mu \mathrm{L}$ volume with standardized components: 20 ng genomic DNA, $0.2 \mu \mathrm{M}$ each of forward and reverse primers, $10 \mu \mathrm{M}$ dNTPs (M/s Bangalore Genei Pvt. Ltd.), 10x buffer (10 mM Tris$\mathrm{Hcl}$ ( $\mathrm{pH} 8.3$ ), $50 \mathrm{mM} \mathrm{KCl}, 1.5 \mathrm{mM} \mathrm{MgCl}_{2}$ ), and 3 units of Taq DNA polymerase (M/s Bangalore Genei Pvt. Ltd.). After amplification, a volume of $3 \mu \mathrm{L}$ of loading buffer was added to each of the amplified products. The amplified products were run on $3.0 \%$ high resolution agarose gel, stained with ethidium bromide following the protocol of Sambrook et al. [23], and were visualized in a gel documentation system.

2.3. Data Analysis. Data analysis was done by scoring of bands. The alleles were scored individually based on comparison in the molecular ladder. The size of the amplicons was compared using a $100 \mathrm{bp}$ ladder. Each band generated by SSR primers was considered as an independent locus. Clearly resolved unambiguous bands were scored visually for their presence or absence with each primer. The scores were obtained in the form of a matrix with " 1 " and " 0 " indicating the presence and absence of bands, respectively. Based on the number of polymorphic bands, percentage polymorphism was calculated for each primer.

The genetic associations between varieties were evaluated by calculating Dice's similarity coefficient for pairwise comparisons based on the proportions of shared bands produced by the primers [24]. Similarity matrix was generated using the NTSYS-PC software, version 2.0 [25]. The similarity coefficients were used for cluster analysis and dendrogram was constructed by the Unweighted Pair-Group method (UPGMA) [26]. Shannon's Information Index, expected and observed heterozygosity, unbiased expected heterozygosity, fixation index, principal component analysis (PCA), and analysis of molecular variance (AMOVA) were worked out for the coconut populations using the software GenAlEx 6.5 [27]. For PCA, genetic distance was calculated from the allele data and the genetic distance was plotted as PCA using GenAlEx.

\section{Results}

In the present study, phylogenetic analysis was carried out using 50 palms that belong to three distinct coconut populations, one a cultivar (WCT) and two ecotypes, namely, ANR and BDK. The 17 SSR primers employed for the study gave clear, unambiguous bands and the data derived were used for further analysis. The details of banding patterns produced in the accessions are given in Table 1. A total of 
TABLE 1: SSR primers, their sequences, banding patterns, and percent polymorphism.

\begin{tabular}{|c|c|c|c|c|c|}
\hline Sl. no. & Primer & Primer sequence $\left(5^{\prime}-3^{\prime}\right)$ & Number of bands & Number of polymorphic bands & Polymorphism (\%) \\
\hline 1 & CAC2 & $\begin{array}{l}\text { AGCTTTTTCATTGCTGGAAT } \\
\text { CСССТCCAATACATTTTTCC }\end{array}$ & 4 & 4 & 100 \\
\hline 2 & CAC3 & $\begin{array}{l}\text { GGCTCTCCAGCAGAGGCTTAC } \\
\text { GGGACACCAGAAAAAGCC }\end{array}$ & 3 & 3 & 100 \\
\hline 3 & CAC4 & $\begin{array}{l}\text { CCCCTATGCATCAAAACAAG } \\
\text { CTCAGTGTCCGTCTTTGTCC }\end{array}$ & 4 & 4 & 100 \\
\hline 4 & CAC6 & $\begin{array}{l}\text { TGTACATGTTTTTTGCCCAA } \\
\text { CGATGTAGCTACCTTCCCC }\end{array}$ & 3 & 3 & 100 \\
\hline 5 & CAC8 & $\begin{array}{c}\text { ATCACCCCAATACAAGGACA } \\
\text { AATTCTATGGTCCACCCACA }\end{array}$ & 3 & 3 & 100 \\
\hline 6 & CAC10 & $\begin{array}{l}\text { GGAACCTCTTTTGGGTCATT } \\
\text { GATGGAAGGTGGTAATGCTG }\end{array}$ & 3 & 3 & 100 \\
\hline 7 & $\mathrm{CAC} 13$ & $\begin{array}{l}\text { GGGTTTTTTAGATCTTCGGC } \\
\text { CTCAACAATCTGAAGCATCG }\end{array}$ & 4 & 4 & 100 \\
\hline 8 & $\mathrm{CNZ1}$ & $\begin{array}{l}\text { ATGATGATCTCTGGTTAGGCT } \\
\text { AAATGAGGGTTTGGAAGGATT }\end{array}$ & 4 & 4 & 100 \\
\hline 9 & CNZ2 & $\begin{array}{l}\text { CTCTTCCCATCATATACCAGC } \\
\text { ACTGGGGGGATCTTATCTCTG }\end{array}$ & 4 & 4 & 100 \\
\hline 10 & CNZ3 & $\begin{array}{l}\text { CATCTTTCATCATTTAGCTCT } \\
\text { AAACCAAAAGCAAGGAGAAGT }\end{array}$ & 4 & 4 & 100 \\
\hline 11 & CNZ4 & $\begin{array}{l}\text { TATATGGGATGCTTTAGTGGA } \\
\text { CAAATCGACAGACATCCTAAA }\end{array}$ & 4 & 4 & 100 \\
\hline 12 & CNZ5 & $\begin{array}{l}\text { CTTATCCAAATCGTCACAGAG } \\
\text { AGGAGAAGCCAGGAAAGATTT }\end{array}$ & 4 & 4 & 100 \\
\hline 13 & CNZ6 & $\begin{array}{l}\text { ATACTCATCATCATACGACGC } \\
\text { CTCCCACAAAATCATGTTATT }\end{array}$ & 4 & 4 & 100 \\
\hline 14 & CNZ10 & $\begin{array}{l}\text { CCTATTGCACCTAAGCAATTA } \\
\text { AATGATTTTCGAAGAGAGGTC }\end{array}$ & 4 & 4 & 100 \\
\hline 15 & CnCir56 & $\begin{array}{l}\text { AACCAGAACTTAAATGTCG } \\
\text { TTTGAACTCTTCTATTGGG }\end{array}$ & 4 & 4 & 100 \\
\hline 16 & CnCirH9 & $\begin{array}{l}\text { CACAATCCTTACATCAAA } \\
\text { TCTCAAGTTCTTACAGCAGT }\end{array}$ & 3 & 3 & 100 \\
\hline 17 & CnCirG4 & $\begin{array}{l}\text { AGTATAGTCACGCCAGAAAA } \\
\text { AAACCCATAACCAGCAAG }\end{array}$ & 4 & 4 & 100 \\
\hline & Total & & 63 & 63 & \\
\hline & Average & & 3.70 & 3.70 & \\
\hline
\end{tabular}

63 bands were produced by 17 primers, with an average of 3.70 bands/primer. Polymorphism was calculated for all the 17 primers after scoring the bands. All the 17 primers showed $100 \%$ polymorphism.

The similarity index, based on Dice's coefficient, was obtained after pair wise comparison of the three coconut populations. The percentage similarity varied between the palms. Maximum similarity was seen between ANR6 and ANR5 (0.97) palms and minimum similarity was seen in BDK16 and ANR1 (0.30) (data not shown). Cluster analysis, based on UPGMA, was performed using NTSYS software in order to obtain a dendrogram. On clustering, it was found that all the three populations formed two major clustersone containing all WCT and a few BDK palms, while the second cluster exclusively contained BDK palms (Figure 1). In general, palms of ANR, BDK, and WCT grouped together according to the population; however, a few palms did show intergroup affinity. Two palms (ANR1 and WCT8) stood outside their respective clusters. A group of five palms of Annur ecotype clustered separately and this group showed more affinity towards WCT. The palms of BDK ecotype were all clustered together except for one palm that aligned with Annur group. WCT palms were mostly clustered together but one palm aligned with BDK and three palms with ANR ecotype. Among palms studied from BDK, four palms showed affinity towards ANR and WCT palms. Remaining palms of $\mathrm{BDK}$ were clustered in a different group. However, one WCT palm (WCT 8) showed variation from all other WCT palms and grouped with BDK ecotype. Other WCT palms were mostly clustered together showing affinity towards ANR palms. The intergroup affinity might be due to sharing of alleles between the three coconut populations studied. The clustering shows that ANR and BDK ecotypes were two separate populations with clear distinction, with just one palm of BDK (BDK 1) showing affinity towards ANR. It is also evident from the clustering that ANR ecotype is 


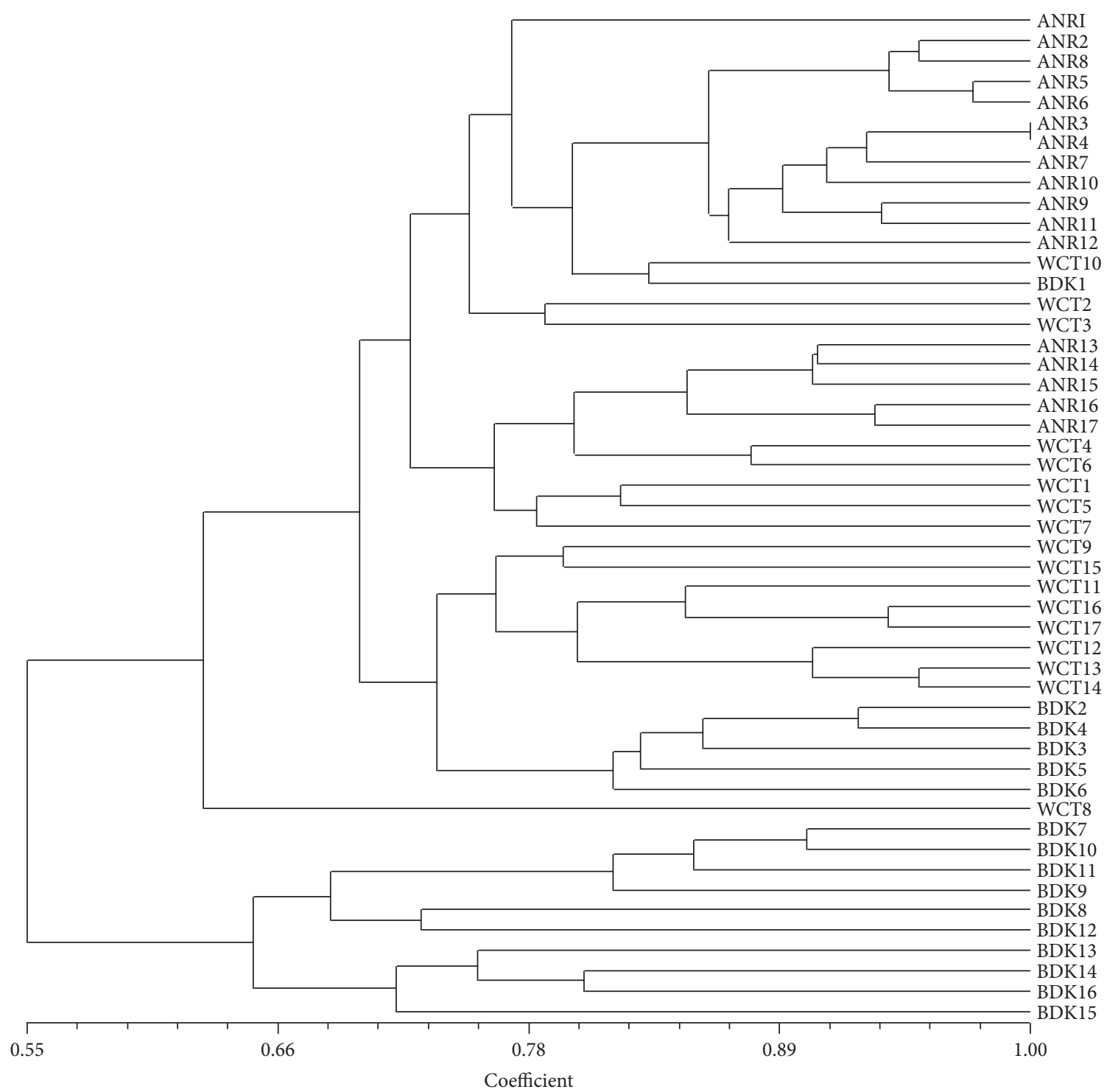

FIGURE 1: UPGMA phylogenetic tree constructed based on Dice's coefficient showing the genetic relationships among the three coconut populations.

closer to WCT than BDK ecotype. When the populations were considered individually, WCT palms clustered at $61 \%$ similarity, ANR palms at $70 \%$ similarity, and BDK palms at $58 \%$ similarity.

Population-wise mean Shannon's Information Index ranged from 0.513 (ANR) to 0.712 (BDK) and the mean observed heterozygosity from 0.257 (ANR) to 0.339 (BDK) (Table 2). The mean unbiased expected heterozygosity (uHe) ranged from 0.325 (ANR) to 0.442 (BDK). Mean fixation index $\left(F_{\mathrm{ST}}\right)$ ranged from 0.205 to 0.372 (Table 2). Pairwise population matrix of Nei's genetic identity calculated using GenAlEx program showed a higher average identity between ANR and WCT (0.92) than between WCT and BDK (0.869) and ANR and BDK (0.783) (Table 3). The AMOVA estimation based on 99 permutations using GenAlEx showed a significant $(P=0.01)$ within population variation $(79 \%)$ compared to among population variation (21\%) (Table 4).
For a deeper understanding of the clustering pattern of the coconut populations, we also carried out genetic distance-based principal component analysis (PCA) using GenAlEx. The results showed clear segregation of all the three populations into different quadrates of the PCA (Figure 2). The first and second axes accounted for 85.13 and $14.87 \%$ of the total inertia, respectively. As shown in Figure 2, the first axis separated BDK from the other two populations, while the second axis separated WCT from the other two populations.

\section{Discussion}

Ecotypes are groups of similar populations within the same plant species that are adapted to certain climatic and edaphic conditions. Coconut has been cultivated for centuries in India and the long history of its cultivation along the length 
TABLE 2: Shannon's Information Index, expected and observed heterozygosity, unbiased expected heterozygosity, and fixation index for the three populations.

\begin{tabular}{lccccc}
\hline Population & $I$ & $H_{o}$ & $H_{e}$ & $\mathrm{u} H_{e}$ & $F_{\mathrm{ST}}$ \\
\hline ANR & & & & & \\
$\quad$ Mean & 0.513 & 0.257 & 0.315 & 0.325 & 0.205 \\
$\quad$ SE & 0.066 & 0.060 & 0.041 & 0.043 & 0.110 \\
WCT & & & & & \\
Mean & 0.708 & 0.339 & 0.427 & 0.440 & 0.244 \\
SE & 0.061 & 0.052 & 0.037 & 0.038 & 0.092 \\
BDK & & & & & \\
Mean & 0.712 & 0.284 & 0.428 & 0.442 & 0.372 \\
SE & 0.062 & 0.057 & 0.035 & 0.036 & 0.105 \\
\hline
\end{tabular}

$I=$ Shannon's Information Index $=-1 * \operatorname{Sum}(\mathrm{pi} * \operatorname{Ln}(\mathrm{pi}))$.

$H_{o}=$ observed heterozygosity $=$ Number of Hets $/ N$.

$H_{e}=$ expected heterozygosity $=1-\operatorname{Sum~} \mathrm{pi}^{\wedge} 2$.

$\mathrm{u} H_{e}=$ unbiased expected heterozygosity $=(2 N /(2 N-1)) * H_{e}$.

$F=$ fixation index $=\left(H_{e}-H_{o}\right) / H_{e}=1-\left(H_{o} / H_{e}\right)$,

where pi is the frequency of the $i$ th allele for the population and Sum pi ${ }^{\wedge} 2$ is the sum of the squared population allele frequencies.

TABle 3: Pairwise population matrix of Nei's genetic identity.

\begin{tabular}{llll}
\hline ANR & WCT & BDK & \\
1.000 & & & ANR \\
0.920 & 1.000 & & WCT \\
0.783 & 0.869 & 1.000 & BDK \\
\hline
\end{tabular}

TABLE 4: Analysis of molecular variance in the coconut populations.

\begin{tabular}{lccccc}
\hline Source & df & SS & MS & Est. Var. & $\%$ \\
\hline Among pops & 2 & 176.652 & 88.326 & 4.330 & $21 \%$ \\
Within pops & 47 & 760.768 & 16.187 & 16.187 & $79 \%$ \\
\hline Total & 49 & 937.420 & & 20.517 & $100 \%$ \\
\hline
\end{tabular}

and breadth of the country has resulted in development of many ecotypes, which are generally named or known by the location where they are grown. These ecotypes are likely to have developed certain adaptation to the particular environment conditions in which they have been growing for a long time and possess a rich source of valuable genes for coconut breeding. It is important to identify and conserve these ecotypes, which could withstand the vagaries of nature and still perform better in terms of growth and yield.

West Coast Tall (WCT) coconut population developed on the West coast of India and came to be known by the region where it was cultivated. Though the origin of WCT is not traceable to any area from where it spread, it is obvious that sea journey by nuts was involved in its spread. The cultivar over the years moved from coastal region to the interior areas, which also resulted in further adaptation and diversity in the cultivar. Such adapted WCT populations in certain localities are designated with local names by farmers to differentiate it from other WCT populations. Annur, Bedakam, Kuttiyadi, Attingal, and Kanjirappally are some of these. The variability shown by WCT and ecotypes derived from it might be genetic or due to physiological factors such as climatic change,

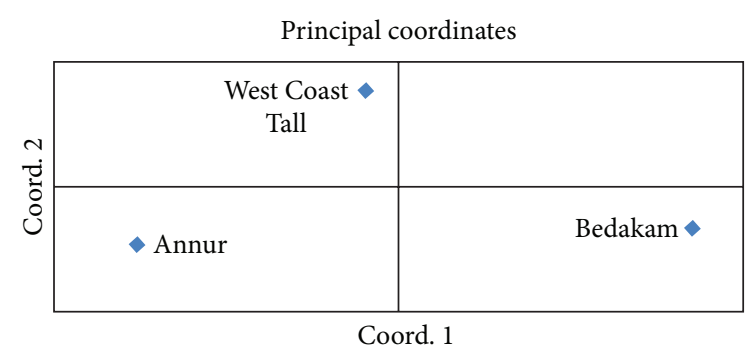

FIgURE 2: Diagram of PCA based on Nei's genetic distance.

$\mathrm{pH}$ of the soil, annual rainfall, or any other environmental factors or even human involvement. These coconut ecotypes may possess higher variability which might be an important source for plant breeding, in comparison to the present day cultivars, which have been specifically chosen for their growth performance under certain specific environment.

Molecular markers play an important role in conservation and use of plant genetic resources. Molecular markers are relatively independent of environment. DNA-based markers are a way of exploring the genetic relations between populations and these markers have acted as versatile tools in various fields. Among the various molecular markers currently available, microsatellite markers are the most popular because they are reproducible, enabling their parallel analysis in different laboratories and exchange of the resulting data [28]. Also, microsatellites form an ideal marker system creating complex banding patterns by simultaneously detecting multiple DNA loci. They have been used successfully by many researchers to characterize the genetic diversity of the coconut population $[18,21]$.

With the objective of deciphering the diversity among and within WCT populations from Kerala region, in the present study, Annur and ecotypes were compared with WCT populations using SSRs. On clustering, it was found that the two ecotypes and WCT formed two major clusters. Annur, Bedakam, and WCT grouped separately, in general, with a few palms showing intergroup affinity. However, most of the Bedakam palms were grouped in separate cluster proving that Annur and Bedakam ecotypes were two separate populations. It is also evident from the clustering that Annur ecotype was closer to WCT than to Bedakam ecotype. Pair-wise population matrix of Nei's genetic identity also revealed a higher average identity between ANR and WCT than between WCT and BDK and ANR and BDK.

The comparison of average observed and expected heterozygosity values did not show great differences between the three coconut populations studied. All the three populations displayed smaller observed than expected heterozygositiesinbreeding may be a factor contributing to this. Among the three populations, palms of ANR ecotype displayed more genetic similarity amongst themselves, with lower observed heterozygosity and fixation index $\left(F_{\mathrm{ST}}\right)$ compared to the other two populations.

The values of heterozygosities obtained in this study confirm that the coconut ecotypes represent an important reservoir of genetic diversity. The three populations showed 
significant genetic differentiation, as indicated by $F_{\mathrm{ST}}$ values, indicating that a high level of differentiation for the alleles has occurred in members of the subpopulation compared to the total population, and therefore members of the subpopulation tend to carry unique alleles compared to the total population. The among population variation was more than within population variation, based on AMOVA calculations, suggesting very rare genetic exchange between the populations, at least in recent history.

Diversity in the original WCT population allowed it to spread in to different ecoregions resulting in the evolution of ecotypes suitable for the local environment and its subsequent adaptation. The result of molecular characterization revealed significant differences in midland and coastal growing palms. The WCT and ecotypes might have differed due to genetic factors or adaptation resulting from environmental variations like climatic change, $\mathrm{pH}$ of the soil, annual rainfall, or any other environmental factors or even human interventions.

One of the important prerequisites for evolutionary change is genetic variation as in its absence populations lack the capacity to evolve. Within a single species, natural selection, coupled with heterogeneity in its habitat, might result in multiple ecotypes, which are genetically distinct [29]. The total genetic variation of a species is likely to be distributed among populations as the impact and direction of natural selection varies from one to another, due to environmental variation and genetic drift [30]. Therefore, with germplasm conservation programmes, it is imperative to accurately measure the amount of genetic diversity and its distribution within and between populations. To these ends, molecular markers provide an efficient and unbiased estimate of these statistics, free of environment effects. Molecular characterization of genetic diversity provides base information which could be utilized in selection of a promising range of accessions for different breeding programs. The microsatellites used in this study appeared to possess a significant potential in this respect. This is one of the first studies to probe the diversity of coconut ecotypes using molecular markers. The results of this study may be used in developing a strategy for conservation of these ecotypes and their utilization in future coconut breeding programmes.

\section{Conflict of Interests}

The authors declare that there is no conflict of interests regarding the publication of this paper.

\section{Acknowledgments}

The authors thank Director, CPCRI, Kasaragod, for his guidance and facilities provided. The authors also thank the farmers and extension personnel from Annur and Bedakam for their cooperation.

\section{References}

[1] L. H. Jones, "Perennial vegetable oil crops," in Agricultural Biotechnology: Opportunities for International Development, pp. 213-224, CAB International, Wallingford, UK, 1990.

[2] J. G. Ohler, "Coconut, a tree of life," Plant Production and Protection Paper, 1984.

[3] D. V. Liyanage, "Preliminary studies on the floral biology of the coconut palm," Tropical Agriculture, vol. 105, pp. 171-175, 1949.

[4] K. Satyabalan, "Yield variation in west coast tall coconut palms: yield attributes which cause variation in annual yield of nuts in the palms of different yield groups," Indian Coconut Journal, vol. 1, pp. 5-8, 1993.

[5] P. Coomans, "Influence of climate factors on seasonal fluctuations of coconut production," Oleagineux, vol. 30, no. 4, pp. 153157, 1975.

[6] D. B. Murray, "Coconut palm," in Ecophysiology of Tropical Crops, P. T. Alvin and T. T. Kozlowski, Eds., pp. 24-27, Academic Press, New York, NY, USA, 1977.

[7] K. V. Kasturi Bai and A. Ramadasan, "Changes in the levels of carbohydrates as a function of environmental variables in hybrids and tall coconut palm," in Coconut Research and Development, N. M. Nair, Ed., pp. 203-209, Wiley Eastern, New Delhi, India, 1983.

[8] V. Rajagopal, A. Ramadasan, K. V. Kasturi Bai, and D. Balasimha, "Influence of irrigation on leaf water relations and dry matter production in coconut palms," Irrigation Science, vol. 10, no. 1, pp. 73-81, 1989.

[9] K. V. Kasturi Bai, V. Rajagopal, C. D. Prabha, M. J. Ratnambal, and M. V. George, "Evaluation of coconut cutivars and hybrids for dry matter production," Journal of Plantation Crops, vol. 24, pp. 23-28, 1996.

[10] C. Jayasekara, N. P. A. D. Nainanayake, and K. S. Jayasekara, "Photosythetic characteristic and productivity of coconut palm," Journal of Plantation Crops, vol. 24, pp. 538-547, 1996.

[11] K. N. Krishna Kumar, Coconut phenology and yield response to climate variability and change [Ph.D. thesis], Cochin University of Science and Technology, Kerala, India, 2011.

[12] K. Ganesamurthy, C. Natarajan, and M. Jayaramachandran, "Genetic diversity and its exploitation in coconut improvement," in Proceedings of the National Conference on AgroBiodiversity, Conducted by National Biodiversity Authority Chennai, February 2006.

[13] U. Parthasarathy, A comparative study of coconut cultivation in coastal and inland River Plain Ecosystem of Kasaragod District of Kerala and Kamrup District of Assam [Ph.D. thesis], Gauhati University, Assam, India, 2004.

[14] A. H. D. Brown, "Isozymes, plant population genetic structure and genetic conservation," Theoretical and Applied Genetics, vol. 52, no. 4, pp. 145-157, 1978.

[15] G. R. Ashburner, W. K. Thompson, G. M. Halloran, and M. A. Foale, "Fruit component analysis of south pacific coconut palm populations," Genetic Resources and Crop Evolution, vol. 44, no. 4, pp. 327-335, 1997.

[16] C. Schlotterer and D. Tautz, "Slippage synthesis of simple sequence DNA," Nucleic Acids Research, vol. 20, no. 2, pp. 211215, 1992.

[17] R. Rivera, K. J. Edwards, J. H. A. Barker et al., "Isolation and characterization of polymorphic microsatellites in Cocos nucifera L," Genome, vol. 42, no. 4, pp. 668-675, 1999. 
[18] B. Teulat, C. Aldam, R. Trehin et al., "An analysis of genetic diversity in coconut (Cocos nucifera) populations from across the geographic range using sequence-tagged microsatellites (SSRs) and AFLPs," Theoretical and Applied Genetics, vol. 100, no. 5, pp. 764-771, 2000.

[19] L. Perera, J. R. Russell, J. Provan, and W. Powell, "Use of microsatellite DNA markers to investigate the level of genetic diversity and population genetic structure of coconut (Cocos nucifera L.)," Genome, vol. 43, no. 1, pp. 15-21, 2000.

[20] M. K. Rajesh, P. Nagarajan, B. A. Jerard, V. Arunachalam, and R. Dhanapal, "Microsatellite variability of coconut accessions (Cocos nucifera L.) from Andaman and Nicobar Islands," Current Science, vol. 94, no. 12, pp. 1627-1631, 2008.

[21] C. Remany, Cataloging and categorization of unexploited ecotypes of coconut grown in Kerala [Ph.D. thesis], Mahatma Gandhi University, Kerala, India, 2003.

[22] M. K. Rajesh, B. A. Jerard, P. Preethi et al., "Development of a RAPD-derived SCAR marker associated with tall-type palm trait in coconut," Scientia Horticulturae, vol. 150, no. 4, pp. 312316, 2013.

[23] J. Sambrook, E. F. Fritsch, and T. Maniatis, Cloning: A Laboratory Manual, Cold Spring Harbor laboratory, 1989.

[24] L. Dice, "Measures of the amount of ecologic association between species," Ecology, vol. 26, pp. 297-302, 1945.

[25] F. J. Rohlf, "NTSYS-pc numerical taxonomy and multivariate analysis system version 2.0. owner manual," 1997.

[26] P. H. A. Sneath and R. R. Sokal, Numerical Taxonomy: The Principles and Practice of Numerical Classification, W. H. Freeman, San Francisco, Calif, USA, 1973.

[27] R. Peakall and P. E. Smouse, "GenAlEx 6.5: genetic analysis in excel. Population genetic software for teaching and research-an update," Bioinformatics, vol. 28, pp. 2537-2539, 2012.

[28] P. K. Gupta, H. S. Balyan, P. C. Sharma, and B. Ramesh, "Microsatellites in plants: a new class of molecular markers," Current Science, vol. 70, no. 1, pp. 45-54, 1996.

[29] Y. B. Linhart and M. C. Grant, "Evolutionary significance of local genetic differentiation in plants," Annual Review of Ecology and Systematics, vol. 27, pp. 237-277, 1996.

[30] M. J. Lawrence and N. Rajanaidu, "The genetic structure of natural populations and sampling strategy," in Proceedings of the International Workshop on Oil Palm Germplasm and Utilization, pp. 15-26, Selangor, Malaysia, 1985. 

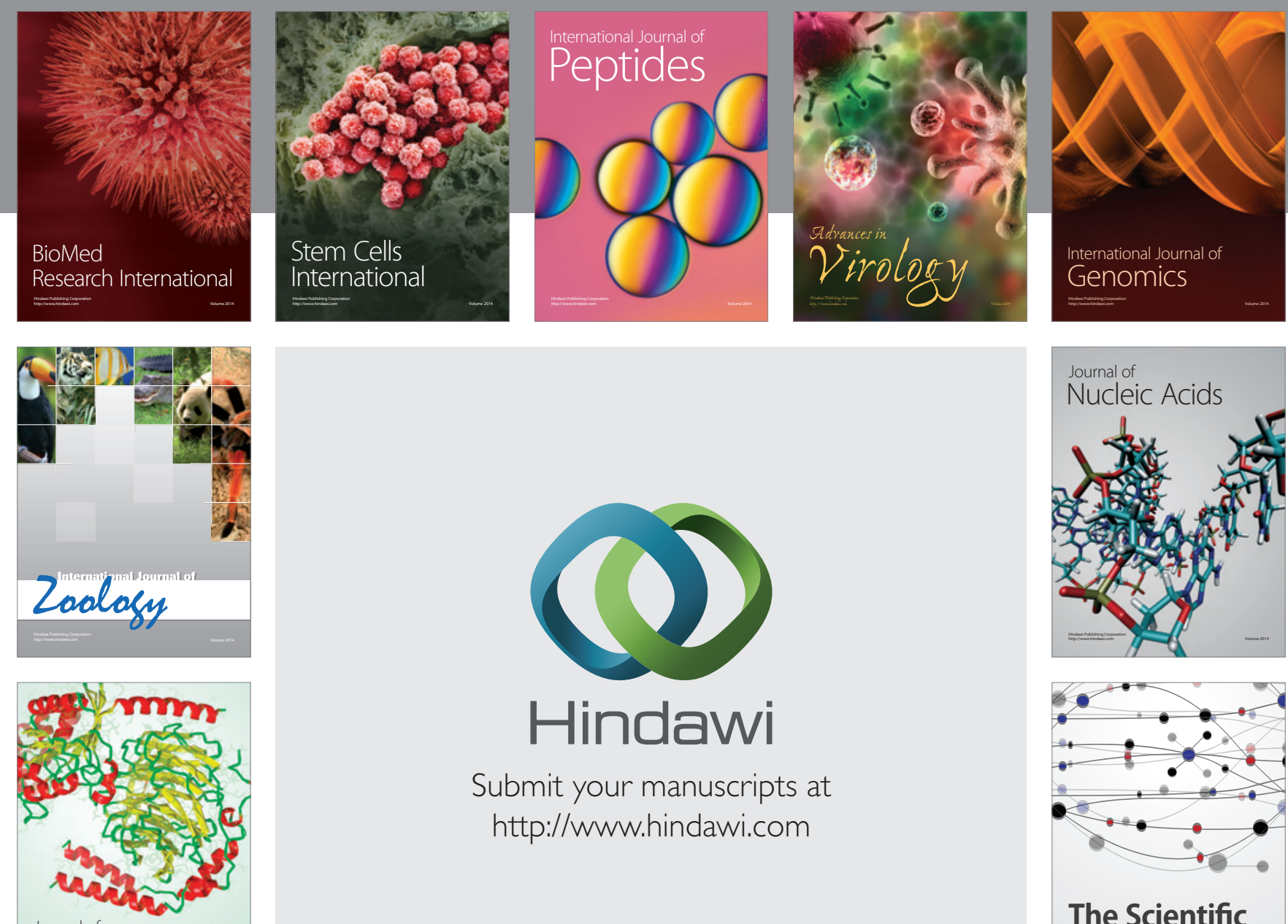

Submit your manuscripts at

http://www.hindawi.com

Journal of
Signal Transduction
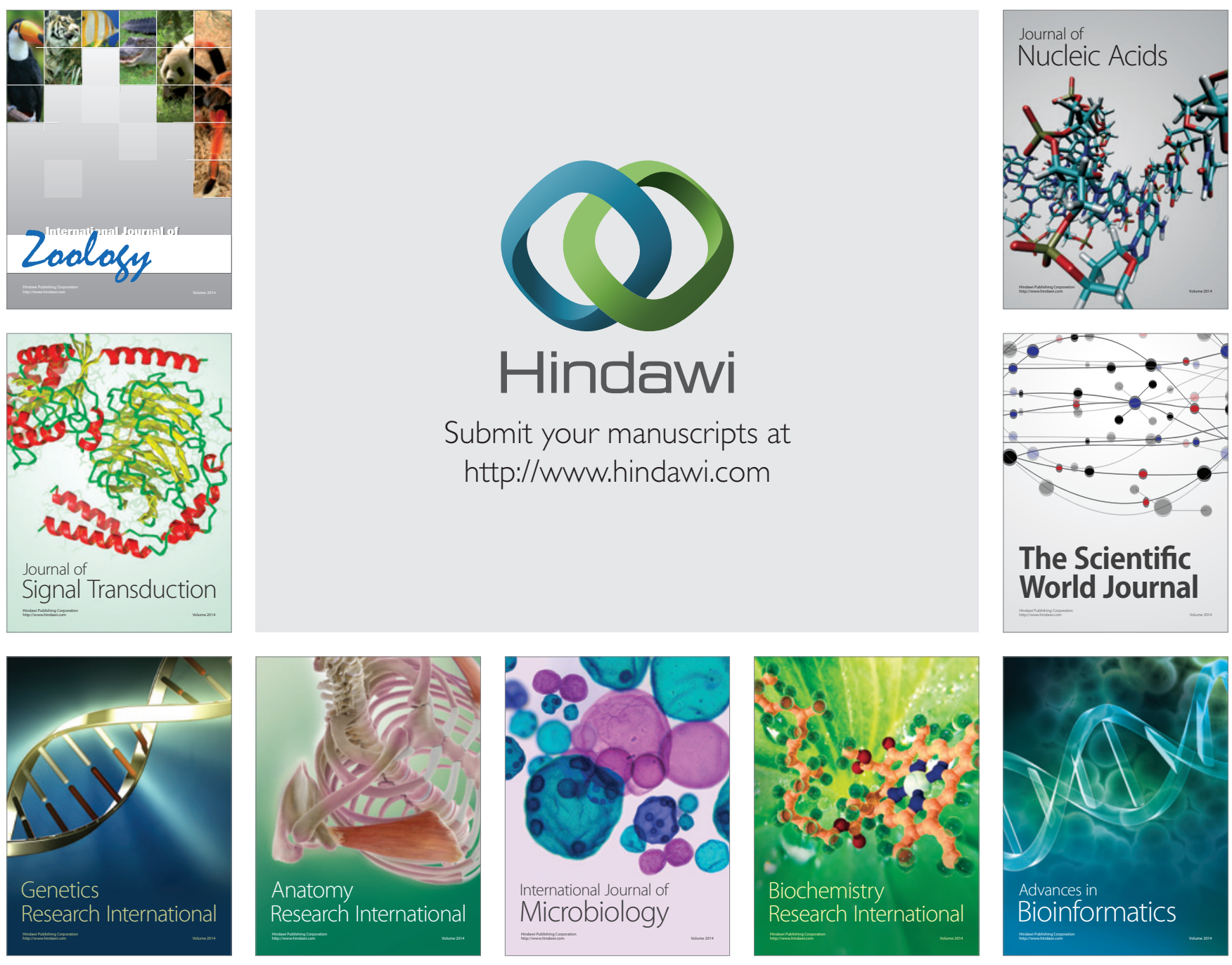

The Scientific World Journal
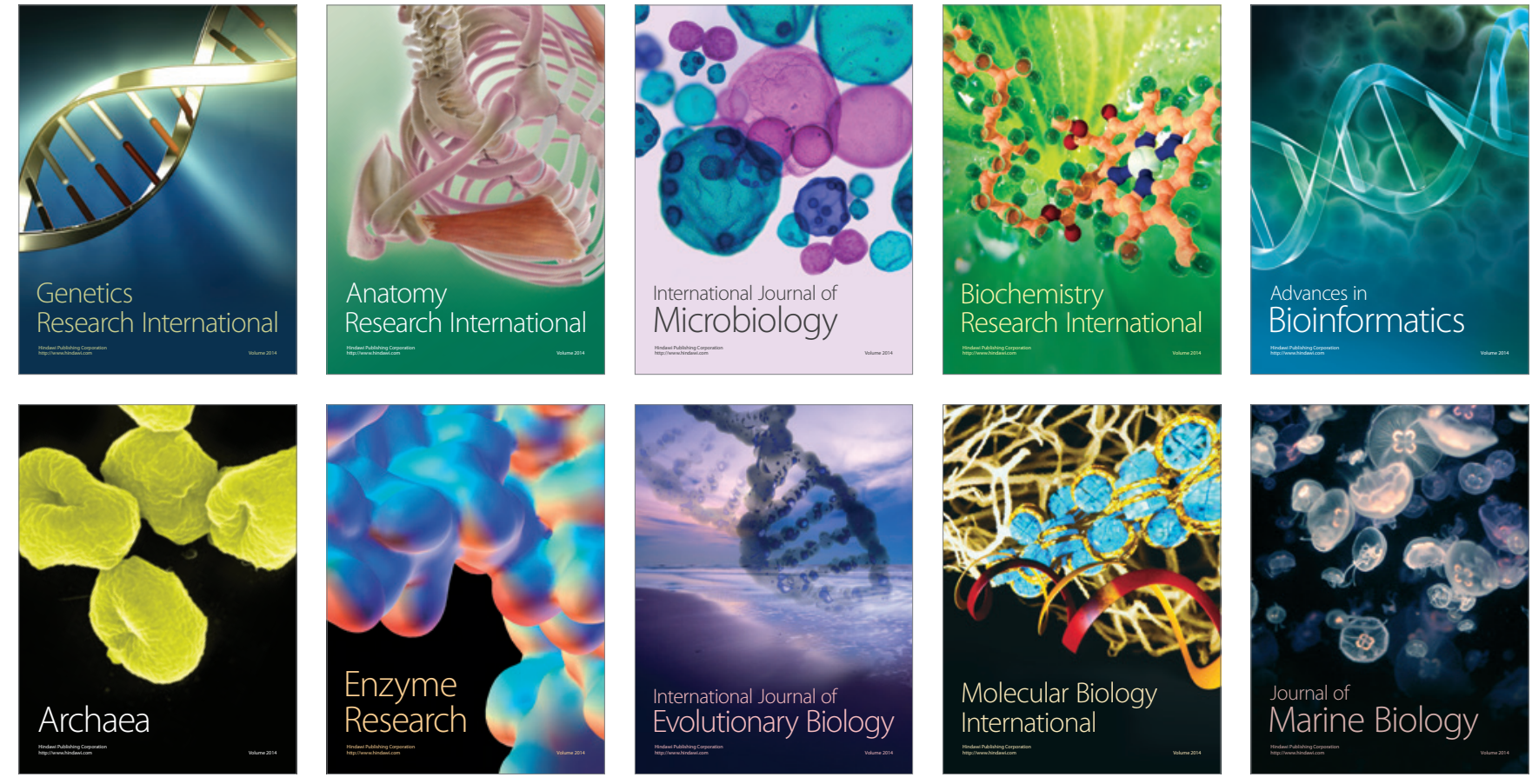